CORRECTION

\title{
Correction to: Cyborg Persons: Humanity Played in a Different Key
}

Steve Fuller ${ }^{1}$

Published online: 3 March 2021

(c) The Author(s) 2021

\section{Correction: Postdigital Science and Education https://doi.org/10.1007/s42438-020-00214-4}

The article was published with an error in the reference entry of Haraway, D. (1985/1991) and Wiener, N. (1948/1961). Thus, this erratum is presented to fix this error.

The original article has been corrected.

The original article can be found online at https://doi.org/10.1007/s42438-020-00214-4.

\section{Steve Fuller}

s.w.fuller@warwick.ac.uk

1 University of Warwick, Coventry, UK 